\title{
Compiling comprehensive national health statistics in a fragmented health information system: lessons learned from Lebanon
}

M.K. Asmar, ${ }^{\text {J.S. Yeretzian' }{ }^{1} \text { and A. Rady }}{ }^{2}$

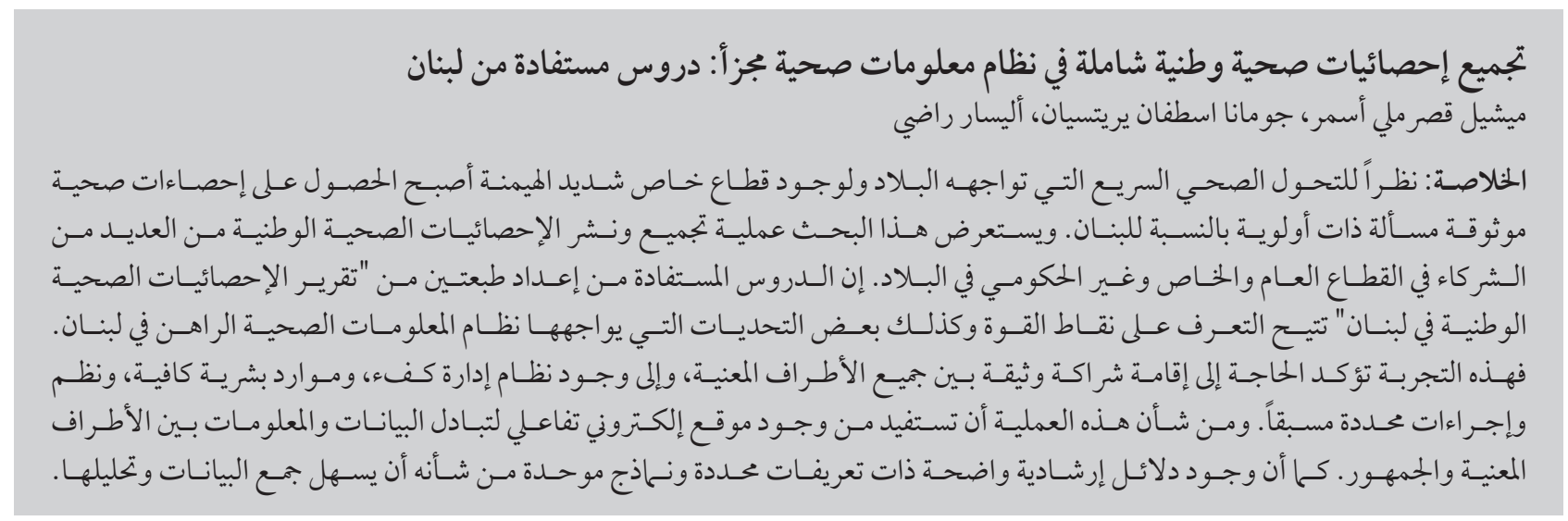

ABSTRACT In view of the rapid health transition faced by the country and a highly dominant private sector, the issue of obtaining reliable health statistics is becoming a priority for Lebanon. This paper reviews the process of compiling and disseminating national health statistics from the multitude of public, private and nongovernmental partners in the country. The lessons learned from preparing two editions of the National health statistics report in Lebanon allow identification of some challenges and strengths of the current health information system in Lebanon. The experience emphasizes the need for a close partnership with all stakeholders, an efficient management system, adequate human resources and predefined systems and procedures. The process would benefit from having an interactive website for exchange of data and information among stakeholders and the public. The existence of clear guidelines with consistent definitions and standardized forms would also facilitate the collection and analysis of data.

Compilation de statistiques sanitaires nationales et exhaustives dans un système d'information sanitaire fragmenté : les enseignements tirés de l'expérience du Liban

RÉSUMÉ Face à la transition sanitaire rapide dans le pays et à un secteur privé fortement dominant, l'obtention de statistiques de santé fiables devient une priorité au Liban. Le présent article analyse le processus de compilation et de diffusion des statistiques de santé nationales fournies par une multitude de partenaires publics, privés et non gouvernementaux dans le pays. Les enseignements tirés de la préparation de deux éditions du rapport sur les statistiques sanitaires nationales au Liban ont permis d'identifier certaines forces et faiblesses du système d'information sanitaire actuel dans le pays. L'expérience souligne la nécessité d'un partenariat étroit entre les parties prenantes, d'un système de gestion efficace, de ressources humaines adéquates ainsi que de systèmes et de procédures prédéfinis. La création d'un site Internet interactif pour l'échange de données et d'informations entre les parties prenantes et le public constituerait un avantage pour le processus. En outre, l'existence de recommandations claires, de définitions cohérentes et de formulaires normalisés faciliterait également le recueil et l'analyse des données. 


\section{Introduction}

Statistics are essential in any process of evidence-based and informed policies and decisions (1). It is often mentioned that Lebanon lacks the accurate and relevant health statistics that are necessary for strategic decision-making. However, significant efforts to improve the health information system have been made by the Lebanese Ministry of Public Health (MoPH) over the past few years $(2,3)$. These include periodic birth statistics reports, annual health bulletins on selected indicators as well as reports on services and vertical programmes delivered through the primary health care network supported by the MoPH. In addition, a geographical information system for health was introduced, but updated erratically, and several departments were computerized to allow easier access to health data such as billing, drug dispensing and other data. Moreover, an effort to unify databases between different public funders, such as the National Social Security Fund and the $\mathrm{MoPH}$, was also achieved to ensure transparency and accuracy of information $(2,4)$. In an attempt to improve reporting on communicable diseases and hospital-based mortality and morbidity, the Epidemiological Surveillance Unit at the MoPH has greatly expanded its sources of data by including hospitals, primary health care centres and public schools. However, compliance with reporting requirements is suboptimal.

Health statistics in Lebanon are also generated from other sources. The Central Administration of Statistics which is mandated to produce national data and statistics including those related to health suffers from both a heavy bureaucracy and understaffing and underfunding, which limit its capacity to fulfil its mission. In addition, there is an abundance of small-scale health studies, generally limited to specific population groups and geographical areas. These studies are usually not reproducible, not representative and often incomplete, thus limiting the generalization of the results. Moreover, a significant number of indicators and variables are estimates or extrapolations. In general, health information from both the public and private sectors is fragmented and difficult to access.

In the health care field, valid and reliable information contributes to improving the quality of any intervention in the health sector, whether at the level of policy, planning, service delivery or impact assessment. Given the multitude of public, private and nongovernmental partners in health, the issue of obtaining reliable health statistics is becoming a priority for Lebanon, especially in view of the rapid health transition faced by the country and the highly dominant private health care sector.

The deficiencies in the health information systems, as described above, highlighted the importance of having an exhaustive national health statistics document that could be used as a reference by all concerned actors. This led to the publication of the first edition of the National health statistics report in Lebanon in 2004, which was subsequently updated and enriched in 2012. Each of these editions was a 3-year endeavour, published by the Institute of Health Management and Social Protection at the Saint-Joseph University of Beirut (IGSPS-USJ) in collaboration with the Italian Development Cooperation and the MoPH for the first edition (5) and the MoPH and the Lebanon country office of the World Health Organization (WHO) for the second edition (6).

This article describes the experience of compiling and disseminating health information from multiple sources and draws on lessons learned through the challenges encountered and the opportunities observed. It is too early to make a formal evaluation of the process, which should be done by evaluators external to the process, and so the main intent behind this article is to summarize and share the experience.

\section{Method for compiling health information data}

The first edition of the National health statistics report in Lebanon was a nonexhaustive compilation of existing health data. No similar project had been previously undertaken in the country. The objective was to provide a document that could on the one hand support decision-makers and planners and on the other hand offer the public reliable information and an overview of the Lebanese health sector. The report presented the available health data, the main health problems of the population and identified the public and private sources of health statistics in the country. The ultimate goal of this first edition was to be a first step towards the development of a health information system.

Two main reasons justified the publishing of a second edition. First, there was the positive feedback received from several users of the first edition, mentioning the importance and helpfulness of such a report in their daily work. Second, was the interest shown by the $\mathrm{MoPH}$ and the WHO to produce an updated edition to enhance the quality and comprehensiveness of the previous report.

The second edition of the report presented the range and types of data available as well as their evolution and trends over time. It was structured in such a way as to provide information on all the components of a health system. It described the health situation of the country in relation to the Millennium Development Goals and facilitated comparisons at both the national and international levels. Moreover, this edition highlighted the existing gaps in the Lebanese health information system and emphasized the main issues to be developed.

A team consisting of a physician, a health administration professional (project manager), a representative from the 
$\mathrm{MoPH}$ and two management trainees was responsible for the first edition.

The first step was the elaboration of a list of private and public institutions in the health sector. Contacts with various institutions, either by phone or through direct visits, were made by the IGSPS-USJ team, under the auspices of the MoPH. Health statistics pertaining to resources, services and results were requested as well as annual activity reports. Statistics were selected, taking into account mainly the relevance of the data, their nature, reliability, completeness and periodicity. The data were collected using a standard format that defined the origin, context, objectives, data collection method, periodicity of the data and field of interest. Tables were then developed and descriptive comments written. Information was collected from 22 private and public sources, including ministries, professional orders and syndicates, universities, nongovernmental organizations and international organizations.

Before publication, two audits were done, one by the team, to check compliancy of the data in terms of content, analysis and relevance. In its final form, the document included 22 chapters covering the 22 sources of health data identified.

For the second edition, the team responsible for the report included the same project manager, a biostatistician, two Master's students in management, reviewers and a secretary. The development of the second edition began by building on the experience from the first report and analysing the recommendations and suggestions received from the stakeholders and users of the first edition. A formal proposal with a new presentation scheme was elaborated and submitted to the IGSPS-USJ research committee and WHO Lebanon country office for funding.
After updating the list of people and institutions to approach, data were collected from over 100 private and public sources, including ministries, universities, nongovernmental organizations and international organizations, and from publications, including surveys, reports, statistical bulletins and utilization reports.

Formal letters were sent to introduce the project and request access to data and information related to health. Follow-up was done through various means such as phone calls, emails and faxes. This phase was the longest and most time-consuming. The gathering of information was done simultaneously for all data pertaining to one topic. A data retrieval form was developed and sent to key individuals within the chosen organizations. These forms were then collected, and data from different sources was compiled and unified whenever possible.

\begin{tabular}{|c|c|c|}
\hline & First edition & Second edition \\
\hline Methods & $\begin{array}{l}\text { - Developing a list of institutions/sources of } \\
\text { - } \text { Establth statistics } \\
\text { sources } \\
\text { - Collecting existing data on health } \\
\text { - Selecting the data } \\
\text { - Presentation of data by institution } \\
\text { - Elaborating the tables } \\
\text { - Vriting the comments } \\
\text { - Validation of final documents }\end{array}$ & $\begin{array}{l}\text { - Updating the list of institutions/sources } \\
\text { of health statistics } \\
\text { - Establishing contacts with institutions/ } \\
\text { - } \text { sources } \\
\text { - Sollecting existing data on health } \\
\text { - Standardization of data and definitions } \\
\text { - Presentation of data by topics } \\
\text { - Elaborating the tables } \\
\text { - Writing the comments } \\
\text { - Scientific and technical validation of final } \\
\text { documents }\end{array}$ \\
\hline Number of chapters & 22 & 5 \\
\hline Scope of chapters & Compilation of information & $\begin{array}{l}\text { Compilation of data and integration of } \\
\text { information }\end{array}$ \\
\hline Duration of data collection & 2 years & 2 years \\
\hline Duration of drafting/ editing & 1 year & 1 year \\
\hline Nature of chapters & Descriptive & Descriptive and analytical \\
\hline Team & $\begin{array}{l}\text { - Physician } \\
\text { - Health administration professional } \\
\text { - Ministry of Public Health representative } \\
\text { - Two management trainees }\end{array}$ & $\begin{array}{l}\text { - Project manager } \\
\text { - Biostatistician } \\
\text { - Two data collection agents, reviewers } \\
\text { - Secretary }\end{array}$ \\
\hline Data sources & 22 private and governmental sources & $\begin{array}{l}\text { More than } 100 \text { private and governmental } \\
\text { sources }\end{array}$ \\
\hline Funding & Italian Development Cooperation & $\begin{array}{l}\text { Saint-Joseph University of Beirut } \\
\text { World Health Organization }\end{array}$ \\
\hline
\end{tabular}


Primary data for each chapter were compiled in tables and graphs in order to facilitate understanding and utilization. Secondary data that seemed useful were added in the text. The main concern was to ensure the validity, reliability and compatibility of the data, while minimizing the risk of misinterpretation. Graphs were used to identify possible trends over time.

The editing consisted of describing each theme first within its general context and then more specifically within the Lebanese one. This was followed by an interpretation of all the tables and graphs. A technical and scientific review by WHO was obtained for all the tables and graphs, as well as the chapter content. Approval of the $\mathrm{MoPH}$ was also received for the overall document.

The second edition document consisted of five main sections:

- Chapter 1 focused on the description of the method used.

- Chapter 2 presented Lebanon in terms of geographical location and sociodemographic structure and described the evolution of its health system, the Millennium Development
Goals for Lebanon as well as the public health regulations for Lebanon.

- Chapter 3, which was the core component of the document, focused on health population indicators, such as mortality, morbidity, risk behaviours, health status of different subgroups of the population and indicators of the health system dealing with infrastructure, human resources, national health programmes, funding and pharmaceuticals.

- Chapter 4 discussed three determinants of health: poverty, employment and environment.

- Chapter 5 gave a brief overview of the national and international partners working in the health sector.

Table 1 compares and contrasts the two editions.

\section{Lessons learned}

These experiences have emphasized the strengths and weaknesses of the current Lebanese health statistics system. The national health statistics reports confirm that health statistics in Lebanon exist, that they are exhaustive for certain topics, that they are generated by researchers and competent authorities and that they are available through several sources. The findings based on both reports are summarized in the SWOT (strengths, weaknesses, opportunities and threats) analysis in Figure 1.

A rapid assessment of the state of health statistics in Lebanon shows that even though health statistics exist at the national level they are still limited, incomplete, scattered and difficult to access. In fact, sometimes they are even contradictory and therefore hinder a comprehensive and in-depth view of the Lebanese health sector. Work in this sector, though abundant, is still difficult and riddled with red tape. Government organizations, nongovernmental organizations and private researchers are not always eager to share their data and benefit from each other's experiences. Perhaps one of the hardest tasks in this compilation was obtaining the data itself and then finding it in a usable or compatible form. Very often, and especially with public institutions, the whole process had to be done several times, either because the person initially contacted was no longer in his/her position or

\begin{tabular}{|c|c|}
\hline STRENGTHS & WEAKNESSES \\
\hline $\begin{array}{l}\text { - Availability of data } \\
\text { - Abundance of data in certain fields } \\
\text { - Presence of qualified human resources }\end{array}$ & $\begin{array}{l}\text { - } \text { Limited national data } \\
\text { - Incomplete data } \\
\text { - Contradictory data } \\
\text { - Scattered data } \\
\text { - Absence of common denominators } \\
\text { - } \text { Difficulty of access } \\
\text { - Lack of dissemination }\end{array}$ \\
\hline OPPORTUNITIES & $\begin{array}{l}\text { THREATS } \\
\end{array}$ \\
\hline $\begin{array}{l}\text { - Awareness of the importance of health statistics } \\
\text { - Existence of a will for improvement } \\
\text { - High demand for quality data } \\
\text { - Concern for transparency }\end{array}$ & $\begin{array}{l}\text { - Lack of funds } \\
\text { - Turnover of human resources } \\
\text { - Limited coordination and cooperation } \\
\text { - Absence of a solid national information system }\end{array}$ \\
\hline
\end{tabular}


because the administrative procedure was interrupted and had to be restarted from the beginning. In addition, most of the data were received in a raw format and varied in their presentation, definitions and/or categories. It was very clear that there was no collaboration among data generators to unify definitions and baseline figures. In fact, for the most part, there was a lack of common denominators resulting in non-standardized definitions and operationalization of indicators. Consequently, a meticulous validation task was necessary in order to standardize the data and to allow for its exploitation and comparison.

Moreover, it was noted that little effort had been put into the standardization and computerization of health information generated by multiple sources. The Internet, although widely used for advertising and social media in Lebanon, has not been exploited to facilitate data retrieval and sharing of health information. As it is, the data obtained could not be manipulated to get more information than that for which it was intended. There was also a problem in terms of the timeliness of the data available. If health information is to be useful, it requires regular updating, maintenance and tracking.

Nevertheless, the relevant stakeholders appeared to be aware of the importance of statistics and the necessity of ensuring the transparency of the results. This was revealed through the growing demand for reliable and valid data in the Lebanese context characterized by limited and restricted funds as well as a poorly coordinated information system. Even though challenging and time-consuming, this task was made easier by the following two factors which counter-balanced the difficulties encountered and ensured the success of the endeavour: the support of the MoPH and of the WHO throughout the process, which was a guarantee of the credibility and quality of the work; and the collaboration among MoPH,WHO and IGSPS-USJ, which greatly facilitated stakeholders' compliance. In addition, the will of all the contributors to share the information greatly enriched the final product. Finally, the availability of funding made the compiling and publication of the report a reality.

Both the reports have provided national benchmarks for the health of the population and have contributed to the dissemination of the available data. Moreover, they have also served to identify the existing gaps and areas to be strengthened. The reports highlight several tracks that could be exploited to develop a national health information system as well as potential obstacles that should be minimized to ensure success.

The experiences with each report have emphasized the need for a close partnership with all stakeholders, an efficient management system, adequate human resources and predefined systems and procedures. The process would benefit from having an interactive website with the dual purpose of exchanging data and information through an intranet system and of disseminating information to and receiving feedback from the public. The existence of clear guidelines with consistent definitions and standardized forms would also facilitate the collection and analysis of data.

The following recommendations can be drawn from these experiences:

- generation of data on a national level, especially in areas where information is scarce or unavailable, such as topics related to mental health, marginalized populations, risk factors and human resources;

- creation of an official body to standardize and validate data generated by different sources;

- strengthening of the existing health statistics system as a basis for a future national health information system; and
- development of adequate mechanisms to disseminate the information and render it accessible to all users and stakeholders.

\section{Conclusion}

The National health statistics report in Lebanon is an important step forward towards increasing multisectorial and multidisciplinary collaboration and coordination among the various parties involved in the health sector. It is also a means to ensure transparency, greater reliability and sound decision-making. Such a publication demonstrates that, contrary to common belief, relevant health statistics are available in Lebanon. However, merely compiling these statistics is no longer sufficient; it is time to utilize them within a broader health strategy. This can only occur if there is a formal involvement and a continuous input to process by all stakeholders in the health sector. Above all, there should be a commitment by all partners to sustain and improve this effort.

While the dream of collecting in one volume the majority of health information available in Lebanon has now been realized, the process should not stop here. Our aim over the coming years is to enrich this tool with additional valuable and accurate health information and to offer a more holistic overview of the health sector in Lebanon. In fact, the experience of publishing these two editions of health statistics should be considered in the short term as the basis for the institutionalization of the national health information system, which would also pave the road in the long term for a more ambitious project the establishment of a national health observatory whose role would be not only to collect information but also to undertake research within the complex health context of this country.

Funding: None.

Competing interests: None declared. 


\section{References}

1. Chan M, Kazatchkine M, Lob-Levyt J, Obaid T, Schweizer J, Sidibe $M$, et al. Meeting the demand for results and accountability: a call for action on health data from eight global health agencies. PLoS Med. 2010 Jan 26;7(1):e1000223. PMID:20126260

2. Country cooperation strategy for WHO and Lebanon 20102015. Cairo: World Health Organization, Regional Office for the Eastern Mediterranean; 2010 (EM/ARD/035/E/12.10) (http://applications.emro.who.int/docs/CCS_Lebanon_2010_EN_14483.pdf, accessed 27 November 2015).

3. Lebanon health profile. Country cooperation strategy at a glance [Internet]. Geneva: World Health Organization; 2010 (http://www.who.int/countryfocus/cooperation_strategy/ ccsbrief_lbn_en.pdf?ua=1, accessed 4 December 2015).
4. Ammar W. Health beyond politics. Cairo: World Health Organization, Regional Office for the Eastern Mediterranean; 2009

5. National health statistics report in Lebanon: 2004 edition. Beirut: Institute of Health Management and Social Protection at Saint-Joseph University; 2004 (http://www.igsps.usj.edu. $\mathrm{lb} /$ docs/recherche/recueil2004.pdf, accessed 27 November 2015).

6. National health statistics report in Lebanon: 2012 edition. Beirut: Institute of Health Management and Social Protection at Saint-Joseph University; 2012 (http://www.igsps.usj.edu. $\mathrm{lb} /$ docs/recherche/recueil12en.pdf, accessed 27 November 2015). 